\title{
New monopole Antennafor Ultra Wideband Applications
}

\author{
D. Ziani Kerarti \\ Laboratory of telecommunications, Department of \\ Electrical and Electronics Engineering,Univ. \\ Abou-BekrBelkaid \\ Tlemcen, Algeria
}

\author{
S. M. Meriah \\ Laboratory of Telecommunications, Department of \\ Electrical and Electronics Engineering,Univ. \\ Abou-BekrBelkaid \\ Tlemcen, Algeria
}

\begin{abstract}
There has been a flourishing prospect of UWB technology in recent years in both communication and other purposes like microwave imaging and radar applications. Recent studies of UWB antenna structures are specially concentrated on microstrip [1], slot and planar monopole antennas [2]. In this work, a small monopole antenna with diamond shape of the patch $\left(30 \times 26 \mathrm{~mm}^{2}\right)$ printed microstrip fed monopole antenna has been designed, some parameters like return loss (S11), Voltage Standing Wave Ratio (VSWR), radiation pattern has been performed to test the validity of simulation and verify eligibility of the antenna for the wireless communications purpose.
\end{abstract}

The proposed antenna is simulated in CST Microwave Studio and has surpassed the bandwidth of UWB requirement, which is from 3.1 to $10.6 \mathrm{GHz}$, and exhibits good UWB characteristics. The $-10 \mathrm{~dB}$ return loss bandwidth of this antenna element is from $3.34 \mathrm{GHz}$ to more than $19.5 \mathrm{GHz}$.

\section{General Terms}

Return-loss, Voltage Standing Wave Ratio (VSWR), 2D/3D Radiation Pattern, Gain.

\section{Keywords}

Ultra Wideband Antennas(UWB), Planar Monopole Antenna,Finite Integrate Technique (FIT),Method of Moment (MoM).

\section{INTRODUCTION}

Ultra Wideband (UWB) utilizes narrow pulses (on the order of a few nanoseconds or less) for sensing and communication. The Federal Communications Commission (FCC) in the U.S.A allocated the UWB frequency spectrum from 3.1 to $10.6 \mathrm{GHz}$ below the transmitter noise threshold of -41.3 $\mathrm{dBm} / \mathrm{MHz}$ [2], [3]. Antennas are in high demand for various UWB applications such as wireless communications, medical imaging, radar and indoor positioning [4]. This is due to its ability to enable high data transmission rate and low power consumption.

Microstrip patch antenna is frequently used in UWB antenna designs due to its advantages such as lightweight, ease of integration, small size and compact [5]. Many UWB microstrip patch antennas have been discussed in the literature to achieve the requirement for different applications, one of which to increase the bandwidth. Since microstrip patch antennas inherently have narrow bandwidth characteristic, there have been numerous techniques developed for bandwidth enhancement in order to achieve the UWB characteristics [6]. These antennas have been discussed in the literature, for instance, Square-ring slot antenna, dual-band slotted antenna[7][8], and dual-band notched antenna. Other techniques employed to increase the bandwidth of antennas include meandered ground plane, slot loading and fractal antenna [9].

In this paper, the antenna is printed on microstrip substrate with a diamond shape of the patch, which operates in the range of 3.34-19.5 GHz, thus achieving the UWB bandwidth enhancement. Section II describes the basic configuration of the antenna design, whereas Section III discusses a simulated result of the antenna performances. Lastly, the findings of the simulated results are summarized in the conclusion.

\section{ANTENNA GEOMETRY}

Fig.1 shows the geometry of the proposed planar antenna whose parameters have been obtained using commercially available simulations software CST Microwave Studio [10] which contains different techniques and calculation methods. This antenna is printed on FR4 Rogers substrate $\varepsilon_{\mathrm{r}}=4.5$ with thickness $1.6 \mathrm{~mm}$ and size $30 \times 26 \mathrm{~mm}^{2}$ and the antenna feeding structure is $50 \Omega$ microstrip line.

Several techniques have been adopted to acquire large impedance bandwidth including a diamond like triangular radiating patch with five steps of various sizes and a partial ground plane[11]. The feed line is denoted by $W f$.

The patch antenna structure is printed on one side of the FR4 substrate with the ground on the other side. The ground plane is denoted by $G$ and rounded corner with rayon $F$ as shown in "Fig.1".The physical structure of five steps with various dimensions have been adopted to increase the effective electrical length at the lower frequency band (3-4 GHz).

The design parameters such as the patch shape, steps, the feed line width and shape of partial ground plane are optimized to obtain the best return loss[12][13], S11 and impedance bandwidth before determining the best dimensions for the proposed antenna. The dimensions of the antenna structure are as shown in Table 1. 
Table 1. Critical antenna dimensions

\begin{tabular}{|c|c|c|}
\hline \multicolumn{2}{|c|}{ Parameters } & Dimensions (mm) \\
\hline \multirow{4}{*}{ Patch antenna } & $\mathrm{W}$ & 30 \\
\cline { 2 - 3 } & $\mathrm{L}$ & 26 \\
\cline { 2 - 3 } & $\mathrm{W}_{\mathrm{f}}$ & 2,5 \\
\cline { 2 - 3 } & $\mathrm{R}$ & 4,5 \\
\cline { 2 - 3 } & $\mathrm{S}$ & 14 \\
\cline { 2 - 3 } & $\mathrm{Q}$ & 1,5 \\
\hline \multirow{4}{*}{ Ground Plan } & $\mathrm{F}$ & 10 \\
\cline { 2 - 3 } & $\mathrm{G}$ & 9,5 \\
\hline
\end{tabular}

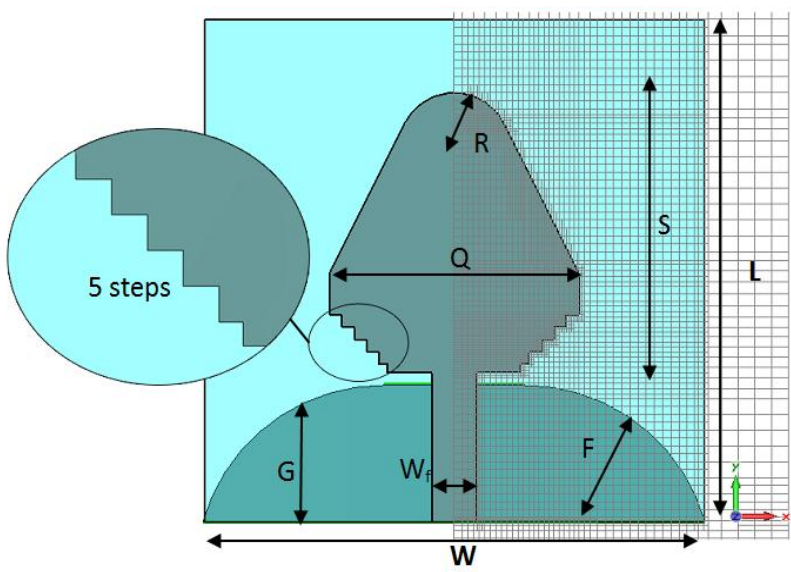

Fig1: geometry of patch antenna (Hexahedral meshing)

\section{RESULTS AND DISCUSSIONS}

To verify the design and optimize antenna dimensions, numerical simulations have been used. Two numerical models of the antenna based on different computational methods have been built in order to cross-verify the results.

The first model is based on the finite integrate technique (FIT). The results have been compared to the second model, which is based on mixed-potential form of the IE formulation in frequency domain. The metal parts as well as the dielectric substrates are modeled using surface integrals. The integral equations of the model are solved using Method of Moment (MoM)in both computational methods are available in the commercial tool CST Microwave.

\subsection{Return Loss, S11}

Figure 2 illustrates the simulated return loss against frequency of the antenna. The results given by the two calculation methods agree with each other with only small differences.

The $-10 \mathrm{~dB}$ bandwidth given by finite integrate technique (FIT) is from $3.34 \mathrm{GHz}$ up to $19.5 \mathrm{GHz}$ while that given by Method of Moment (MoM) is from $3.65 \mathrm{GHz}$ to $19.4 \mathrm{GHz}$. The observed deviation is due to the different numerical modeling and meshing techniques. Nevertheless, the variations are within tolerance, so we could say both computational methods gave us good estimation of the antenna performance.

The plots of the return loss "Fig. 2" of the antenna show that simulated impedance bandwidth is $16.16 \mathrm{GHz}$ (from 3.34 $\mathrm{GHz}$ to $19.5 \mathrm{GHz}$ ), which is equivalent to $141.56 \%$ (FIT) and
$15.75 \mathrm{GHz}$ equivalent to $136.65 \%$ (MoM), both band width are calculated by using relation (1).

$$
\mathrm{BP} \%=2 \times \frac{f_{h}-f_{l}}{f_{h}+f_{l}} \times 100
$$

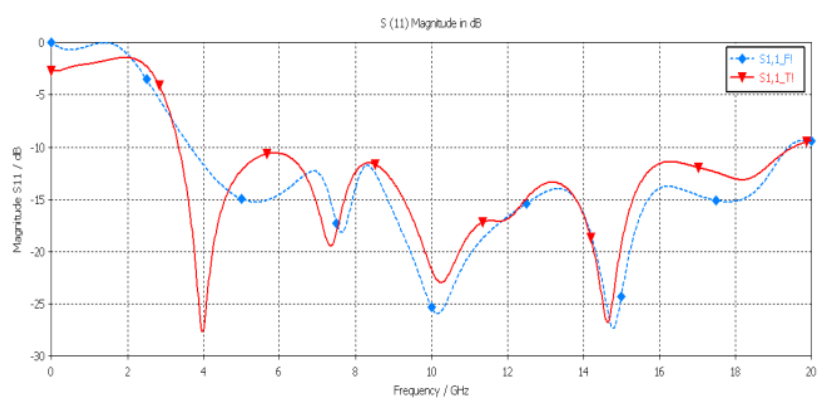

Fig 2: Comparison of the return loss simulated with different methods FIT (T!) and MoM (F!)

\subsection{Voltage Standing Wave Ratio (VSWR)}

Figure 3 illustrates the simulated voltage standing wave ratio (VSWR) against frequency of the antenna. Based on the simulated result, the VSWR value ranges from 1 to 2 throughout the frequency range. Both results are validated because the same frequency regions do fall in $\mathrm{S} 11$ above -10 $\mathrm{dB}$ as is shown in "Fig 2".

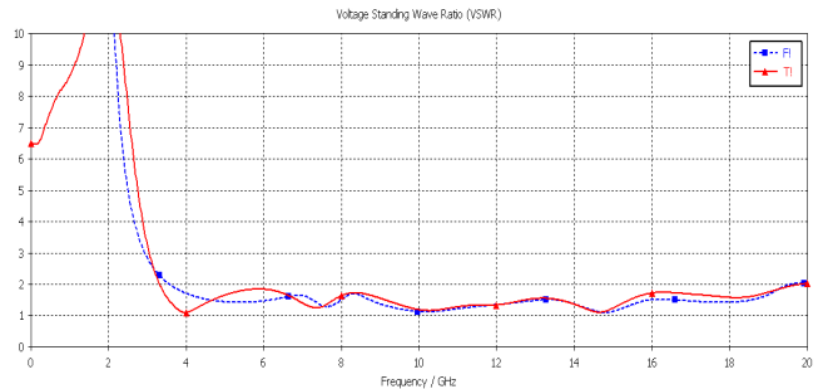

Fig 3:simulated results of voltage standing wave ratio (VSWR) against frequency $(\mathrm{GHz})$.

Overall, this antenna exhibits good UWB characteristics in terms of impedance bandwidth and return loss.

\subsection{Radiation Pattern}

The simulated gain of the antenna for the frequencies between 2 and $20 \mathrm{GHz}$ "Fig 4" shows that the gain increases with frequency and is around $4.61 \mathrm{~dB}$ at $16 \mathrm{GHz}$.

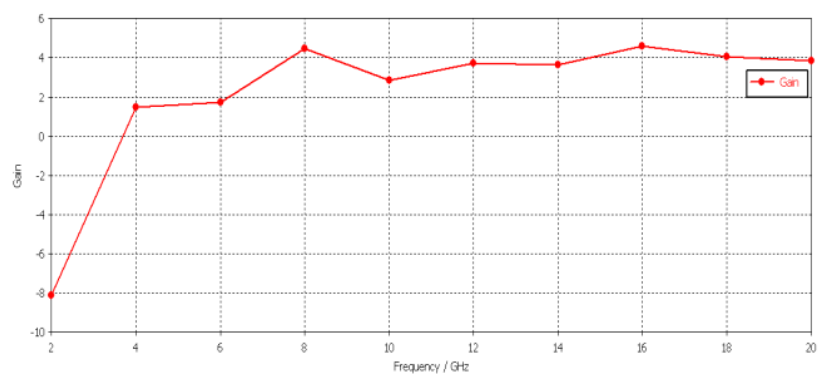

Fig4: simulated results of Gain vs. Frequency.

Figure 5shows two dimensional radiation patterns of the proposed antenna at different frequencies $(2,4,6$ and $8 \mathrm{GHz})$ the antenna presents an omnidirectional (doughnut- 
shaped)radiation patterns in the low frequencies that transforms into diagram directional multi-lobs at higher
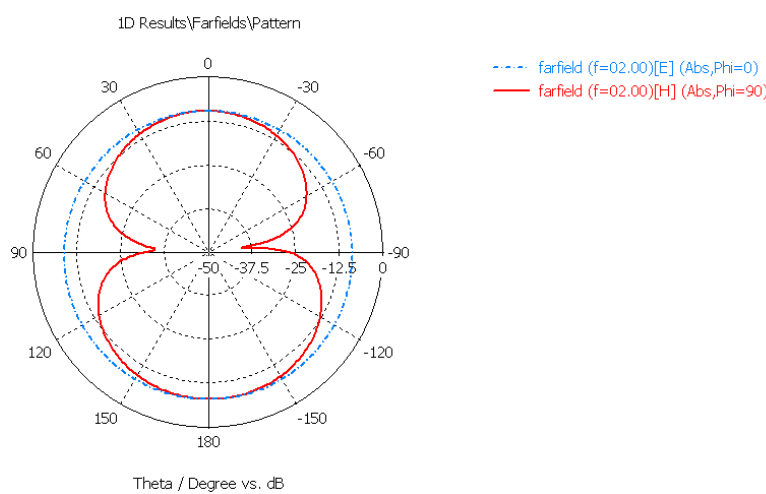

$2 \mathrm{GHz}$

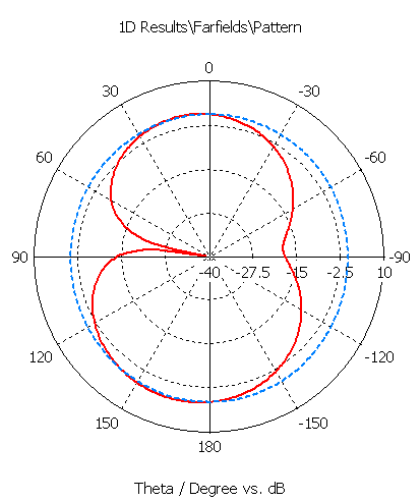

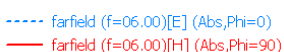

$6 \mathrm{GHz}$

Fig 5: Simulated 2-D radiation pattern (Directivity pattern for phi=0 $(x-z)$ and phi=90 (y-z) planes).

\section{CONCLUSIONS}

The proposed antenna exhibits good UWB characteristics, with its simulated result operating from $3.34 \mathrm{GHz}$ to 19.5 $\mathrm{GHz}$, having fractional bandwidth of more than $141.56 \%$ simulated with two different solvers. The antenna has successfully achieved enhanced UWB bandwidth, in which UWB frequency spectrum covers the range from $3.1 \mathrm{GHz}$ to 10.6 GHz. Besides, it complies with the VSWR range from 1 to 2 throughout the impedance bandwidth, whereas the radiation patterns with stable radiation characteristics. The proposed antenna, with good UWB characteristics and geometrically small nature, easily integrated into a network, is suitable for wireless communication systems and microwave imaging.

Several perspectives seen from this work, trying to increase the operating band and radiation characteristics of the antenna, and our results will be validated with a practical realization.

\section{ACKNOWLEDGMENTS}

We are heartily thankful to our supervisors, friends and family members, whose encouragement, guidance and support from the initial to the final level enabled us to develop an understanding of the subject. Lastly, we offer our regards and blessings to all of those who supported us in any respect during the completion of this paper. frequencies.

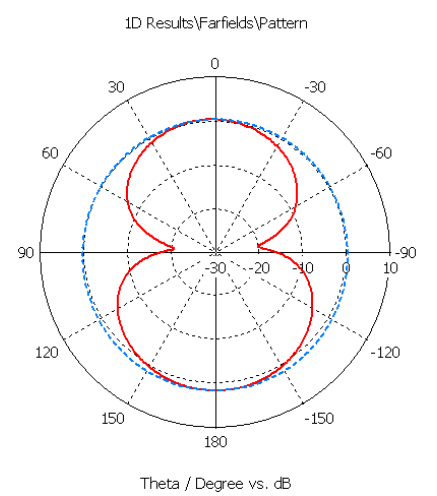

… farfield ( $f=04.00)[E]$ (Abs, Phi $=0$ ) — farfield $(f=04.00)[H]$ (Abs, Phi $=90)$
$4 \mathrm{GHz}$

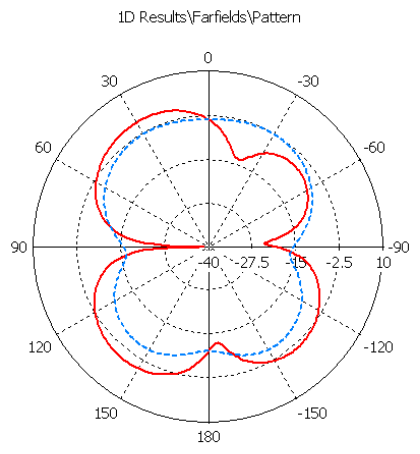

Theta / Degree vs. dB

\section{REFERENCES}

[1] Z. N. e. a. Cheng, "Planar antennas," IEEE Microwave Magazine, vol. 7, pp. 63-73, 2006.

[2] C. A. Balanis, Antenna Theory Analysis and Design 2ed edition. J.Wiley\&Sons, 1997.

[3] Z. N. C. a. M. Y. W. Chia, "Broadband Planar Antennas: Design and Applications," John Wiley \& Sons, Ltd, pp. 180-190, 2006.

[4] V.H.Rumsey, "requency Independant Antennas," in , 1957, pp. 114-118.

[5] W. C. K.F.LEE, Advences in microstrip and printed antennas. J. Wiley \& sons, 1997.

[6] H. G. Schantz, "A Brief History of UWB Antennas," IEEE UWBST Conference.Brownsboro, 2003.

[7] M. D. O. M. B. \&. J. E. B.Allen, Ultra Widbend Antennas And Propagation For Communications, Radar and Imaging. John Wiley \& Sons, 2007.

[8] L.BABOUR, "Etude et Conception d'antennes Ultra Large Bande Miniaturisees en Impulsionnel," $\mathrm{PhD}$ thesis, Polytechnic Institute of Grenoble, 2009.

[9] A.Constantine, Antenna Theory, Analysis and Design. John Wiley \& Sons, Second Edition 2005. 


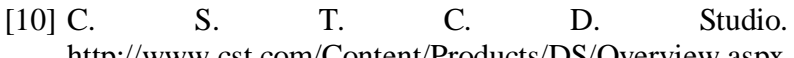
http://www.cst.com/Content/Products/DS/Overview.aspx

[11] S. N. P. I.Hossain, "A Diamond Shaped Small Planar Ultra Wide Band (UWB) Antenna for Microwave Imaging Purpose," IEEE Transaction on Antennas and Propagation, 2007.
[12] D. K. ZIANI, "Etude et conception d'antennes ultra large bande," Magister thesis, Univ.Abou-BekrBelkaid, Tlemcen, july 2011.

[13] D. K. ZIANI, et al., "Small Microstrip Antenna For Ultra Wideband Applications," in International Congress on Telecommunication and Application'12, Bejaia, Algeria, 11 -12 April 2012, pp. 15-18. 